\title{
Renal sympathetic denervation after Symplicity HTN-3 and therapeutic drug monitoring in severe hypertension
}

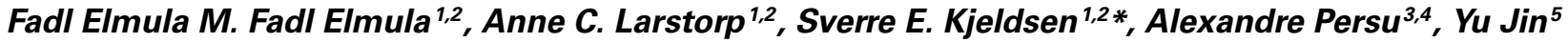 \\ and Jan A. Staessen ${ }^{5,6}$ \\ 1 Departments of Cardiology and Internal Medicine, Oslo University Hospital, Ullevaal, Norway \\ 2 Faculty of Medicine, University of Oslo, Oslo, Norway \\ ${ }^{3}$ Pole of Cardiovascular Research, Institut de Recherche Expérimentale et Clinique, Université Catholique de Louvain, Brussels, Belgium \\ ${ }^{4}$ Division of Cardiology, Cliniques Universitaires Saint-Luc, Université Catholique de Louvain, Brussels, Belgium \\ ${ }^{5}$ Studies Coordinating Centre, Research Unit Hypertension and Cardiovascular Epidemiology, KU Leuven Department of Cardiovascular Sciences, University of \\ Leuven, Leuven, Belgium \\ ${ }^{6}$ VitaK Development and Research, Maastricht University, Maastricht, Netherlands
}

Edited by:

Kate Denton, Monash University,

Australia

Reviewed by:

Jacqueline Kathleen Phillips,

Macquarie University, Australia

Kenju Miki, Nara Women's

University, Japan

Massimo Volpe, University of Rome

Sapienza, Italy

*Correspondence:

Sverre E. Kjeldsen, Oslo University Hospital, Ullevaal, University of

Oslo, PO Box 4950, Nydalen, 0424

Oslo, Norway

e-mail: s.e.kjeldsen@medisin.uio.no
Renal sympathetic denervation (RDN) has been and is still proposed as a new treatment modality in patients with apparently treatment resistant hypertension (TRH), a condition defined as persistent blood pressure elevation despite prescription of at least 3 antihypertensive drugs including a diuretic. However, the large fall in blood pressure after RDN reported in the first randomized study, Symplicity HTN-2 and multiple observational studies has not been confirmed in five subsequent prospective randomized studies and may be largely explained by non-specific effects such as improvement of drug adherence in initially poorly adherent patients (the Hawthorne effect), placebo effect and regression to the mean. The overall blood-pressure lowering effect of RDN seems rather limited and the characteristics of true responders are largely unknown. Accordingly, RDN is not ready for clinical practice. In most patients with apparently $\mathrm{TRH}$, drug monitoring and improvement of drug adherence may prove more effective and cost-beneficial to achieve blood pressure control. In the meantime, research should aim at identifying characteristics of those patients with truly TRH who may respond to RDN.

\section{Keywords: hypertension, antihypertensive drugs, renal denervation, drug monitoring, treatment resistance}

\section{INTRODUCTION}

Renal sympathetic denervation (RDN) has been and is still proposed as a new treatment modality in patients with apparently treatment resistant hypertension (TRH), a condition defined as persistent blood pressure elevation despite prescription of at least 3 antihypertensive drugs including a diuretic (Krum et al., 2009, 2014; Esler et al., 2010). However, with the recent publication of the Symplicity HTN-3 study in the U.S. (Bhatt et al., 2014) it is questioned whether RDN at all lowers blood pressure (Demaria, 2014). During 2014, a total of 5 prospective and randomized studies of RDN showing modest or no effect on blood pressure in patients with TRH have been published or presented. Other recent studies have shown that patients with TRH have surprisingly low drug adherence. The aim of this paper is to review all prospective and randomized studies of RDN in TRH and, and to review the issue of poor drug adherence and suggest therapeutic drug monitoring (TDM) as a costeffective modality to control blood pressure and improve prognosis in this subset of hypertensive patients who are at risk and difficult-to-treat.

Abbreviations: ABPM, ambulatory blood pressure monitoring; RDN, renal sympathetic denervation; TRH, treatment resistant hypertension; TDM, therapeutic drug monitoring.

\section{THE RISE AND FALL OF RENAL DENERVATION IN TREATMENT RESISTANT HYPERTENSION}

The initial enthusiasm followed by the setback of RDN can probably be summarized by a handful of explanations: (1) The role of the sympathetic system in the pathophysiology of hypertension is substantiated by a wealth of experimental and clinical arguments (Julius and Esler, 1975; Eide et al., 1979; Kjeldsen et al., 1981). On this background, enthusiasm surged when an intervention in this system seemed to drastically lower blood pressure. (2) Market-driven industry interests significantly influenced the medical community. (3) Subsequently, pitfalls in the treatment of apparent TRH patients, which are simple but well-known for decades, were suddenly forgotten, including well described phenomena such as the placebo effect, poor drug adherence (Gifford, 1988; Klein, 1988; Ceral et al., 2011) and the Hawthorne effect (Mangione-Smith et al., 2002). Regression to the mean could also be involved which means that abnormal BP values tend to change toward normalization without an underlying biological explanation.

The first and for a long time the only prospective randomized clinical trial in this field, the Symplicity HTN-2 study (Esler et al., 2010), was monitored by Ardian (Medtronic) who collected and processed the data. Usually, when such a task is given to industry, all measures are taken to secure confidence and 
trials are double-blinded (Julius et al., 2004). However, in this case, everything was open, making the trial particularly vulnerable to patient and physician related biases (Howard et al., 2013). In a recent editorial (Shun-Shin et al., 2014), the authors wrote that "measurement of a noisy variable by unblinded optimistic staff is a known recipe for calamitous exaggeration." It is also unfortunate that selection of patients enrolled in Symplicity HTN-2 and evaluation of efficacy were based on office rather than ambulatory blood pressure measurements (ABPM), which is state-of-the art (O'Brien et al., 2013), particularly in resistant hypertension (Persu et al., 2014d). ABPM reduces observer bias and measurement error, minimizes the white-coat effect and has greater reproducibility, and therefore provides a better estimate of a patient's usual blood pressure and cardiovascular prognosis (Kikuya et al., 2007; Salles et al., 2008). Notwithstanding the well-known, major contribution of poor drug adherence to apparently resistant hypertension (Gifford, 1988; Klein, 1988; Ceral et al., 2011), drug adherence was not monitored, either at baseline or during follow-up. This made the study vulnerable to the Hawthorne effect, i.e., patients changing behavior-in this case starting taking their drugs as prescribed -, in response to the intervention and massive attention devoted to them. The lack of blood pressure decrease in the control group also raises concerns. One would indeed suspect that patients in the control group had not taken their medications properly, in order to keep their blood pressure at a higher level that made them eligible for cross-over to RDN group (Azizi et al., 2012; Persu et al., 2012). Finally, placebo effect and regression to the mean must also be taken into account. Noteworthy, the placebo effect is small by using ABPM (Staessen et al., 1996; O'Brien et al., 2013); however, ABPM remains as sensitive to the Hawthorne effect as office blood pressure.

\section{THE ROLE OF INDUSTRY IN PROMOTING RENAL DENERVATION}

Despite the major limitations and potential biases of Symplicity HTN-2, RDN was adopted in hundreds of centers worldwide. Medtronic Inc ${ }^{\circledR}$ (Minneapolis, Minnesota) paid $\$ 800$ million to purchase $\operatorname{Ardian}^{\circledR}$ (Mountain View, California), the company that had developed the technology (Demaria, 2014), and more than 10 companies developed their own RDN systems, five of which obtained the CE mark (Conformité Européenne, European Conformity). CE marking means that the product is assessed before being placed on the market and meets EU safety, health and environmental protection requirements. However, CE marking is unrelated to medical indication at variance with the USA where FDA approves a medical device only when it has been tested and proved effective for a certain medical condition. The procedure was quickly reimbursed in Germany, and later on in Switzerland, Sweden and the Netherlands. While RDN remained an investigational procedure in the U.S., at least 8000 (Lüscher and Mahfoud, 2014), possibly 15,000-20,000 procedures were performed in Europe and in the rest of the world in less than 4 years, most of them using the Ardian -Medtronic ${ }^{\circledR}$ catheter. It may be hypothesized that the massive incomes, generated by selling the Symplicity catheter to enthusiastic Europeans paid for the Symplicity HTN-3 study (Bhatt et al., 2014), required by the FDA before approval of RDN in the U.S. In Symplicity HTN-3, blinding of patients through the use of a sham procedure and wider use of ABPM balanced and limited the differential impact of the Hawthorne, white coat, placebo and regression to the mean effects in both arms, disclosing to the world the true size of blood pressure decrease attributable to RDN, at least in patients meeting the Symplicity criteria; it was less than $2 \mathrm{mmHg}$ systolic based on ABPM.

For all aforementioned reasons, and in view of the complexity and multifactorial character of hypertension, the failure of RDN to normalize or substantially reduce blood pressure in all patients with apparently TRH was a reasonable working hypothesis for us, even before the Medtronic announcement that Symplicity HTN-3 had failed to meet its primary endpoint (http://www. tctmd.com/show.aspx?id=123265). We (Fadl Elmula et al., 2013; Persu et al., 2013a,b) and others (Azizi et al., 2012; Howard et al., 2013) had predicted that the true effect of RDN might have been overestimated and may considerably shrink in properly designed studies (Howard et al., 2013), and that "one size may not fit all" (Persu et al., 2012). In particular, in preliminary analysis of the European Network COordinating research on Renal Denervation (ENCOReD) network (Persu et al., 2014a) we were struck by the imbalance between the $17.6 \mathrm{mmHg}$ decreases in office blood pressure, vs. only $5.9 \mathrm{mmHg}$ for 24 -h ambulatory blood pressure.

\section{FINDING PATIENTS WITH TRUE TREATMENT-RESISTANT HYPERTENSION FOR RESEARCH}

When we set out to investigate the effects of RDN in one of the centers with the longest experience in conducting randomized clinical trials in Europe (Helgeland, 1980), we had thus clearly in mind the limitations of previous studies. We needed a simple and practical way to deal with pitfalls in the recruitment of patients with resistant hypertension into a study protocol: Patients had to qualify for the RDN protocols by having elevated daytime ABPM after witnessed intake of their prescribed blood pressure medication (Fadl Elmula et al., 2013). Meanwhile, a leading hypertension center in Germany (Brinkmann et al., 2012) published a welldocumented series of patients whose blood pressure remained unchanged after RDN. We were thus not surprised when we found no change in either office or ABPM following RDN, first in an open series of six patients (Fadl Elmula et al., 2013), later followed by a randomized study (Fadl Elmula et al., 2014). Patients who were randomly assigned to further improvement of drug treatment guided by non-invasive hemodynamic monitoring had normalized blood pressures (Figures 1, 2). In contrast, patients exposed to RDN experienced only a small and probably partly placebo-induced fall in office and ABPM. The decreases averaged $20 \mathrm{mmHg}$ more for office and $9 \mathrm{mmHg}$ more for ambulatory systolic blood pressure in the hemodynamically guided drug treatment group $(n=10)$ compared to the RDN group $(n=9)$. Because of sustained elevation of AMBP in the RDN treated patients at 6 months of follow-up, we stopped randomization for ethical reason according to a pre-specified decision (Fadl Elmula et al., 2013).

\section{THE PITFALLS WITH RENAL DENERVATION IN TREATMENT RESISTANT HYPERTENSION}

In the absence of solid evidence of efficacy, how can we explain the uncontrolled deployment of RDN in Europe and worldwide (with the notable exception of the U.S. where RDN remained 


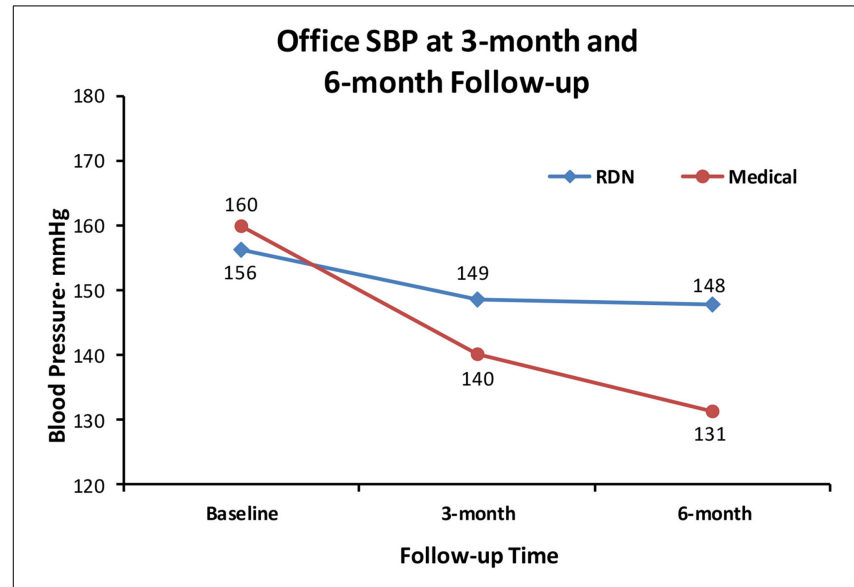

FIGURE 1 | Shows the effect of RDN on office systolic blood pressure (SBP) at 3-month and 6-months of follow-up, compared to drug treatment adjustment guided by non-invasive hemodynamic measurements. Differences were statistically significant (Fadl Elmula et al., 2014), favoring drug treatment adjustment, which is the recommended method to gain blood pressure control in patients with so-called treatment-resistant hypertension (Gifford, 1988).

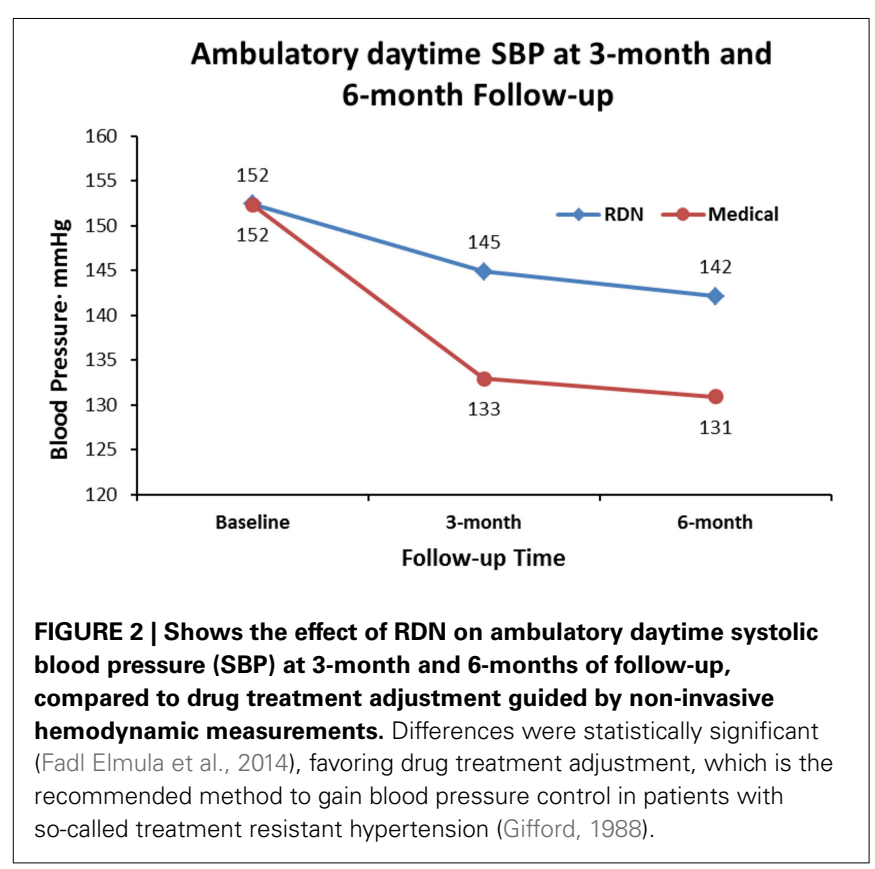

an investigational procedure)? Of course, publications of the Symplicity studies and multiple observational studies, and enthusiastic editorials and reviews in top-ranking journals (Mahfoud et al., 2013; Ott et al., 2013) had a substantial impact, and the lack of strict rules for introduction of device-based therapies in Europe facilitated the large-scale implementation of the technique. However, this phenomenon would have remained limited without the huge promotion by device-producing industry. Probably industry has never launched such a strong campaign to market a new technology before. A multitude of national and international advisory boards organized educational meetings, developed a website (www.poweroverpressure.com) and produced guidelines, and corresponding author of this current review contributed to these. Medical journals were swamped by reviews and meta-analyses showing the powerful blood pressure lowering effects as recorded in observational studies and in the single available randomized study, Symplicity HTN-2. Comments pointing out the defects and inconsistencies in such meta-analysis encountered great delay in getting published (Jin et al., 2014). Many never questioned whether RDN should be implemented, but when it should start in an institution. By all means, the purpose was to disseminate the enthusiasm for RDN from the technically-oriented invasive radiologists and cardiologists who usually had little interest or experience in the treatment of hypertension to the "hypertension establishment." The European Society of Hypertension issued specific guidelines (Schmieder et al., 2012, 2013), but maintained reservations that more data was needed, and eventually it had to be proven that RDN would lower morbidity and mortality before being generally accepted in the treatment of true or apparent TRH.

In the aftermath of Symplicity HTN-3, it has been suggested that the lack of demonstrated efficacy of RDN in Symplicity HTN-3 may be due to lack of statistical power or even to chance (Lüscher and Mahfoud, 2014) or that the trial was well conceived but not rigorously executed (Esler, 2014; Schmieder, 2014; White et al., 2014; Lobo et al., 2015). In particular, a fraction of African American participants increased their antihypertensive medication, contrary to protocol, which masked a potential $\mathrm{BP}$ lowering effect of RDN in contrast to other participants. In addition, legitimate concerns were raised as to whether the denervation procedure was sub-optimal in many cases due to insufficient delivery of appropriate energy in the renal arteries as a consequence of the inexperience of the investigators. However, this criticism is all post-hoc, and the Symplicity HTN-3 findings are after all in line with the other RCTs published and presented in 2014 (Azizi et al., 2014; Desch et al., 2014; Fadl Elmula et al., 2014; Rosa et al., 2015). Furthermore, the Symplicity HTN-3 results are diluted by non-scientific comparisons with the Medtronic ${ }^{\circledR}$ registry (Pathak et al., 2014) which is hampered by all the weaknesses touched upon in this review, and even more as it is a pure industry-ran activity. Finally, while RDN will not become available in the U.S., and ongoing research in Asia was stopped, industry continues to make their catheters available for clinical use and promotes the technique in Europe.

\section{COULD THERE BE RESPONDERS TO RENAL DENERVATION IN HYPERTENSION?}

Does the failure of Symplicity HTN-3 mean the end of RDN? Not necessarily. Indeed, it has been shown in cohorts recruited from the third (The effect of progressive sympathectomy on blood pressure, Bradford Cannon, 1931) until the fifth decade of the last century (Smithwick and Thompson, 1953; Longland and Gibb, 1954) that abdominal sympathectomy associated to splanchnicectomy is effective in the treatment of severe hypertension. Accordingly, research should go on to find the minority of patients who are true responders to RDN, and identify predictors of effective RDN. The European Network COordinating research 
on Renal Denervation (ENCOReD) is set up to include thousands of patients in randomized protocols, observational studies and registries independent of industry. Some early results (Persu et al., 2014a,b) from this joint effort have already been published and suggest that it may be worthwhile searching for potential predictors of response to RDN. When 2 prospective and randomized studies that have been published (Rosa et al., 2015) and reported (Azizi et al., 2014), plus Symplicity Flex, another sham-controlled study very recently reported (Desch et al., 2014) are added to the 3 published studies (Esler et al., 2010; Bhatt et al., 2014; Fadl Elmula et al., 2014) the overall picture shows that RDN is equal to drugs in lowering BP. However, individual data suggests that there may be cause for optimism that some truly responding patients may be identified.

Still, before going ahead, we have to draw the lessons of the RDN story. We must make sure that RDN is beneficial and does no harm. Many patients have probably undergone unneeded procedures. By a careful estimate, 20000 renal arteries have been exposed to ablation in people with hypertension and an increasing number of cases of renal artery stenosis after RDN are being reported (Persu et al., 2014c). It remains to be seen whether the negative news that RDN is not for most people will reach Time Magazine $(\mathrm{Oz}, 2012)$ and Der Spiegel (Blech, 2013), or whether the old lessons (Bramley et al., 2006) remain for clinicians who treat people with hypertension in daily life.

\section{THERAPEUTIC DRUG MONITORING IN RESISTANT HYPERTENSION}

In view of the major contribution of poor drug adherence to apparent $\mathrm{TRH}$, therapeutic drug monitoring (TDM) maybe a useful tool for detecting and reducing non-adherence, leading to substantial blood pressure (BP) improvement in this subset of hypertensive patients. (Chung et al., 2014) have assessed costeffectiveness of TDM using a Markov model based on German data and life statistics to evaluate life-years, quality-adjusted lifeyears (QALYs), costs, and incremental cost-effectiveness ratios in TRH patients receiving either TDM optimized therapy or standard best medical therapy. Efficacy of TDM was modeled by reducing risk of hypertension-related morbidity and mortality. The authors showed that TDM is a cost-effective health care intervention in patients diagnosed with $\mathrm{TRH}$, and that this finding is valid for a wide range of patients, irrespective of age and sex (Chung et al., 2014).

Poor drug adherence in apparent TRH is a serious issue that has drawn the attention of experienced clinicians for many years (Gifford, 1988; Klein, 1988). Recently, in a study of 84 patients taking on average 5 antihypertensive drugs it was shown by measurements that no drug was detectable in the blood in $34.5 \%$ of the patients, and $65.5 \%$ of the patients fulfilled the criteria of non-adherence (Ceral et al., 2011). Other investigators have provided similar results (Jung et al., 2013; Strauch et al., 2013; Tomaszewski et al., 2014). Beyond the clinical challenge of convincing people with severe hypertension to take their antihypertensive medication in order to control their high blood pressure and improve their prognosis, changes in drug adherence over time may have major, unpredictable effects on the results of clinical trials including patients with apparent TRH. People may change their behavior when given special attention in research (the Hawthorne-effect). This may introduce important biases, as patients with assumed TRH but with poor drug adherence, may start taking their drugs when exposed to additional intervention. We postulate that much of the recent controversy with RDN can be explained in this way (Esler et al., 2010; Bhatt et al., 2014).

Clinical assessment of non-adherence in routine practice is challenging (Burnier et al., 2003). Drug adherence is usually investigated using written patient's diary or somewhat more sophisticated by electronic pill boxes, or blood and urine measurements of prescribed drugs. Measurements of drugs can provide interesting information, but are not often used in practical clinical work especially in primary care, and the cost has been prohibitive until recently. Neither patient's diary nor electronic pill boxes are perfectly reliable to ensure drug intake. The only methods that $100 \%$ ensures true drug intake is witnessed drug intake, an approach that may yield quite interesting results in patients with TRH (Fadl Elmula et al., 2013, 2014). However, while witnessed intake of drugs may identify adherent patients for immediate inclusion into a study, this method is not particularly practical in the long-run for the follow-up in clinical practice or research.

In the long run, TDM in body fluids may thus prove the best tool for evaluation and improvement of adherence to drug therapy (Brinker et al., 2014). This approach allows an objective surveillance of patient adherence by repeatedly measuring concentrations of antihypertensive drugs in blood and urine. Moreover, when non-adherent patients were confronted with their low or undetectable drug levels and were provided additional counseling to overcome barriers of adherence, blood pressure control improved considerably without intensification of therapy (Brinker et al., 2014). While several studies as pointed out above focused on the objective exclusion or confirmation of non-adherence, this recent study (Brinker et al., 2014) utilized the information gained from TDM measurements for therapeutic purposes. The TDM results were discussed with the non-adherent patients to explore barriers to adherence and counseling was provided to overcome these barriers. During follow-up, SBP was reduced by $46 \pm 10 \mathrm{mmHg}$ in non-adherent compared to $12 \pm$ $17 \mathrm{mmHg}$ in adherent patients, without intensification of the antihypertensive therapy (Brinker et al., 2014).

TDM identifies and helps to resolve the key problem in many — possibly the majority — of patients with apparent TRHthat is poor adherence to prescribed drug regimen. As previously shown, the cost-effectiveness of this approach is supported by a solid rationale (Chung et al., 2014) and should not be compared to similar analyses of controversial device intervention (Geisler et al., 2012; Dorenkamp et al., 2013; Gladwell et al., 2014) in apparent TRH patients. So far, such analyses were indeed based on Symplicity HTN-2, an unblinded study largely open to the Hawthorne and placebo effects, whose results could not be replicated in any of five randomized trials published or presented in 2014.

\section{REFERENCES}

Azizi, M., Monge, M., Pereira, H., and Sapoval, M. (2014). The French DENERHTN Trial: renal denervation + standardized antihypertensive treatment 
vs. standardized antihypertensive treatment alone in patients with resistant hypertension. J. Hypertens. 32(e-Suppl. 1), e89.

Azizi, M., Steichen, O., Frank, M., Bobrie, G., Plouin, P. F., and Sapoval, M. (2012). Catheter-based radiofrequency renal-nerve ablation in patients with resistant hypertension. Eur. J. Vasc. Endovasc. Surg. 43, 293-299. doi: 10.1016/j.ejvs.2011.11.022

Bhatt, D. L., Kandzari, D. E., O’Neill, W. W., D’Agostino, R., Flack, J. M., and Katzen, B. T. (2014). SYMPLICITY HTN-3 Investigators. A controlled trial of renal denervation for resistant hypertension. N. Engl. J. Med. 370, 1393-1401. doi: 10.1056/NEJMoa1402670

Blech, J. (2013). Vergebens verbrutzelt. Ein Eingriff an den Nierennerven gilt als neues Wundermittel gegen Bluthochdruck. Dabei ist nicht bewiesen, dass die Methode den Patienten wirklich nutzt. Der. Spiegel No. 28, 102-103.

Bradford Cannon, W. (1931). The Effect of Progressive Sympathectomy on Blood Pressure. Available online at: http://www.ncbi.nlm.nih.gov/pubmed/2204236

Bramley, T. J., Gerbino, P. P., Nightengale, B. S., and Frech-Tamas, F. (2006). Relationship of blood pressure control to adherence with antihypertensive monotherapy in 13 managed care organizations. J. Manag. Care Pharm. 12, 239-245.

Brinker, S., Pandey, A., Ayers, C., Price, A., Raheja, P., and Arbique, D. (2014). Therapeutic drug monitoring facilitates blood pressure control in resistant hypertension. J. Am. Coll. Cardiol. 63, 834-835. doi: 10.1016/j.jacc.2013. 10.067

Brinkmann, J., Heusser, K., Schmidt, B. M., Menne, J., Klein, G., and Bauersachs, J. (2012). Catheter-based renal nerve ablation and centrally generated sympathetic activity in difficult-to-control hypertensive patients: prospective case series. Hypertension 60, 1485-1490. doi: 10.1161/HYPERTENSIONAHA.112.201186

Burnier, M., Santschi, V., Favrat, B., and Brunner, H. R. (2003). Monitoring compliance in resistant hypertension: an important step in patient management. J. Hypertens Suppl. 21, S37-S42. doi: 10.1097/00004872-200305002-00007

Ceral, J., Habrdova, V., Vorisek, V., Bima, M., Pelouch, R., and Solar, M. (2011). Difficult-to-control arterial hypertension or uncooperative patients? The assessment of serum antihypertensive drug levels to differentiate non-responsiveness from non-adherence to recommended therapy. Hypertens Res. 34, 87-90. doi: 10.1038/hr.2010.183

Chung, O., Vongpatanasin, W., Bonaventura, K., Lotan, Y., Sohns, C., Haverkamp, W., et al. (2014). Potential cost-effectiveness of therapeutic drug monitoring in patients with resistant hypertension. J. Hypertens. 32, 2411-2421. doi: 10.1097/HJH.0000000000000346

Demaria, A. N. (2014). Reflections on renal denervation. J. Am. Coll. Cardiol. 63, 1452-1453. doi: 10.1016/j.jacc.2014.03.001

Desch, S., Okon, T., Heinemann, T., Kulle, K., Röhnert, K., Sonnenabend, M., et al. (2014). "A randomized sham-controlled trial of renal sympathetic denervation in mild resistant hypertension," in Transcatheter Cardiovascular Therapeutics Meeting, (Washington, DC). Available online at: http://www.medpagetoday. com/MeetingCoverage/TCT/47688

Dorenkamp, M., Bonaventura, K., Leber, A. W., Boldt, J., Sohns, C., and Boldt, L. H. (2013). Potential lifetime cost-effectiveness of catheter-based renal sympathetic denervation in patients with resistant hypertension. Eur. Heart J. 34, 451-461. doi: 10.1093/eurheartj/ehs355

Eide, I., Kolloch, R., DeQuattro, V., Miano, L., Dugger, R., and Van der Meulen, J. (1979). Raised cerebrospinal fluid norepinephrine in some patients with primary hypertension. Hypertension 1, 255-260. doi: 10.1161/01.HYP.1.3.255

Esler, M. (2014). Illusions of thruth in the Symplicity HTN-3 Trial: generic design strengths but neuroscience failing. J. Am. Soc. Hypertens 8, 593-598. doi: 10.1016/j.jash.2014.06.001

Esler, M. D., Krum, H., Sobotka, P. A., Schlaich, M. P., Schmieder, R. E., and Bohm, M. (2010). Renal sympathetic denervation in patients with treatmentresistant hypertension (The Symplicity HTN-2 Trial): a randomised controlled trial. Lancet 376, 1903-1909. doi: 10.1016/S0140-6736(10)62039-9

Fadl Elmula, F. E. M., Hoffmann, P., Fossum, E., Brekke, M., Gjønnæss, E., and Hjørnholm, U. (2013). Renal sympathetic denervation in patients with treatment-resistant hypertension after witnessed intake of medication before qualifying ambulatory blood pressure. Hypertension 62, 526-532. doi: 10.1161/HYPERTENSIONAHA.113.01452

Fadl Elmula, F. E. M., Hoffman, P., Larstorp, A. C., Fossum, E., Brekke, M., and Kjeldsen, S. E. (2014). Adjusted drug treatment is superior to sympathetic renal denervation in patients with true treatment resistant hypertension. Hypertension 63, 691-699. doi: 10.1161/HYPERTENSIONAHA.114.03246
Geisler, B. P., Egan, B. M., Cohen, J. T., Garner, A. M., Akehurst, R. L., and Esler, M. D. (2012). Cost-effectiveness and clinical effectiveness of catheter-based renal denervation for resistant hypertension. J. Am. Coll. Cardiol. 60, 1271-1217. doi: 10.1016/j.jacc.2012.07.029

Gifford, R. W. (1988). An algorithm for the management of resistant hypertension. Hypertension 11, I-171-175. doi: 10.1161/01.HYP.11.3_Pt_2.II101

Gladwell, D., Henry, T., Cook, M., and Akehurst, R. (2014). Cost effectiveness of renal denervation therapy for the treatment of resistant hypertension in the UK. Appl. Health Econ. Health Policy 12, 611-622. doi: 10.1007/s40258-014-0116-7

Helgeland, A. (1980). Treatment of mild hypertension: a five year controlled drug trial. The Oslo study. Am. J. Med. 69, 725-732. doi: 10.1016/00029343(80)90438-6

Howard, J. P., Nowbar, A. N., and Francis, D. P. (2013). Size of blood pressure reduction from renal denervation: insights from meta-analysis of antihypertensive drug trials of 4,121 patients with focus on trial design: the CONVERGE report. Heart 99, 1579-1587. doi: 10.1136/heartjnl-2013-304238

Jin, Y., Persu, A., and Staessen, J. A. (2014). Letter by Jin et al. regarding article, "ambulatory blood pressure changes after renal sympathetic denervation in patients with resistant hypertension". Circulation 129, e499. doi: 10.1161/CIRCULATIONAHA.113.005121

Julius, S., and Esler, M. (1975). Autonomic nervous cardiovascular regulation in borderline hypertension. Am. J. Cardiol. 36, 685-696. doi: 10.1016/00029149(75)90170-8

Julius, S., Kjeldsen, S. E., Weber, M., Brunner, H., Ekman, S., and Hansson, L. (2004). Cardiac events, stroke and mortality in high-risk hypertensives treated with valsartan or amlodipine: main outcomes of the value trial. Lancet 363, 2022-2031. doi: 10.1016/S0140-6736(04)16451-9

Jung, O., Gechter, J. L., Wunder, C., Paulke, A., Bartel, C., and Geiger, H. (2013). Resistant hypertension? Assessment of adherence by toxicological urine analysis. J. Hypertens 31, 766-774. doi: 10.1097/HJH.0b013e32835e2286

Kikuya, M., Hansen, T. W., Thijs, L., Björklund-Bodegård, K., Kuznetsova, T., and Ohkubo, T. (2007). For the IDACO investigators. Diagnostic thresholds for ambulatory blood pressure monitoring based on 10-year cardiovascular risk. Blood Press Monit. 12, 393-395. doi: 10.1097/MBP.0b013e3282f2b53d

Kjeldsen, S. E., Flaaten, B., Eide, I., Helgeland, A., and Leren, P. (1981). Increased peripheral release of noradrenaline and uptake of adrenaline in essential hypertension? Clin. Sci. (Lond). 61(Suppl. 7), 215s-217s.

Klein, L. E. (1988). Compliance and blood pressure control. Hypertension 11, I161-164. doi: 10.1161/01.HYP.11.3_Pt_2.II61

Krum, H., Schlaich, M. P., Böhm, M., Mahfoud, F., Rocha-Singh, K., and Katholi, R. (2014). Percutaneous renal denervation in patients with treatment-resistant hypertension: final 3-year report of the Symplicity HTN-1 study. Lancet 383, 622-629. doi: 10.1016/S0140-6736(13)62192-3

Krum, H., Schlaich, M., Whitbourn, R., Sobotka, P. A., Sadowski, J., and Bartus, K. (2009). Catheter-based renal sympathetic denervation for resistant hypertension: a multicentre safety and proof-of-principle cohort study. Lancet 373, 1275-1281. doi: 10.1016/S0140-6736(09)60566-3

Lobo, M. D., de Belder, M. A., Cleveland, T., Collier, D., Dasgupta, I., Deanfield, J., et al. (2015). Joint UK societies' 2014 consensus statement on renal denervation for resistant hypertension. Heart 101, 10-16. doi: 10.1136/heartjnl-2014-307029

Longland, C. J., and Gibb, W. E. (1954). Sympathectomy in the treatment of benign and malignant hypertension; A review of 76 patients. Br. J. Surg. 41, 382-392. doi: 10.1002/bjs.18004116814

Lüscher, T. F., and Mahfoud, F. (2014). Renal nerve ablation after SYMPLICITY HTN-3: confused at the higher level? Eur. Heart J. 35, 1706-1711. doi: 10.1093/eurheartj/ehu195

Mahfoud, F., Ukena, C., Schmieder, R. E., Cremers, B., Rump, L. C., and Vonend, O. (2013). Ambulatory blood pressure changes after renal sympathetic denervation in patients with resistant hypertension. Circulation 128, 132-140. doi: 10.1161/CIRCULATIONAHA.112.000949

Mangione-Smith, R., Elliott, M. N., McDonald, L., and McGlynn, E. A. (2002). An observational study of antibiotic prescribing behavior and the Hawthorne effect. Health Serv. Res. 37, 1603-1623. doi: 10.1111/1475-6773.10482

O’Brien, E., Parati, G., Stergiou, G., Asmar, R., Beilin, L., and Bilo, G. (2013). European society of hypertension position paper on ambulatory blood pressure monitoring. J. Hypertens 31, 1731-1768. doi: 10.1097/HJH.0000000000000221

Ott, C., Mahfoud, F., Schmid, A., Ditting, T., Sobotka, P. A., and Veelken, R. (2013). Renal denervation in moderate treatment-resistant hypertension. J. Am. Coll. Cardiol. 62, 1880-1886. doi: 10.1016/j.jacc.2013.06.023 
$\mathrm{Oz}, \mathrm{M}$. (2012). Pressure relief. This year brings a breakthrough procedure to fight hypertension. Time Mag. 179, 40.

Pathak, A., Ewen, S., Fajadet, J., Honton, B., Mahfoud, F., and Marco, J. (2014). From SYMPLICITY HTN-3 to the renal denervation global registry: where do we stand and where should we go? Eur. Intervent. 10, 21-23. doi: 10.4244/EIJV10I1A4

Persu, A., Azizi, M., Burnier, M., and Staessen, J. A. (2013a). Residual effect of renal denervation in patients with truly resistant hypertension. Hypertension 62, 450-452. doi: 10.1161/HYPERTENSIONAHA.113.01632

Persu, A., Jin, Y., Azizi, M., Baelen, M., Völz, S., and Elvan, A. (2014a). On behalf of the European Network Coordinating research on REnal denervation (ENCOReD). Blood pressure changes after renal denervation at 10 European expert centers. J. Hum. Hypertens 28, 150-156. doi: 10.1038/jhh.2013.88

Persu, A., Jin, Y., Baelen, M., Vink, E., Verloop, W. L., and Schmidt, B. (2014b). European Network Coordinating research on REnal Denervation (ENCOReD) Consortium. Eligibility for renal denervation: experience at 11 European expert centers. Hypertension 63, 1319-1325. doi: 10.1161/HYPERTENSIONAHA.114.03194

Persu, A., Jin, Y., Fadl ElMula, M. F. E., Jacobs, L., Renkin, J., and Kjeldsen, S. E. (2014c). Renal denervation after symplicity HTN-3: an update. Curr. Hypertens Rep. 16, 460. doi: 10.1007/s11906-014-0460-x

Persu, A., O'Brien, E., and Verdecchia, P. (2014d). Use of ambulatory blood pressure measurement in the definition of resistant hypertension: a review of the evidence. Hypertens. Res. 37, 967-972. doi: 10.1038/hr.2014.83

Persu, A., Renkin, J., Asayama, K., O’Brien, E., and Staessen, J. A. (2013b). Renal denervation in treatment-resistant hypertension: the need for restraint and more and better evidence. Expert Rev. Cardiovasc Ther. 11, 739-749. doi: $10.1586 /$ erc. 13.52

Persu, A., Renkin, J., Thijs, L., and Staessen, J. A. (2012). Renal denervation: ultima ratio or standard in treatment-resistant hypertension. Hypertension 60, 596-606. doi: 10.1161/HYPERTENSIONAHA.112.195263

Rosa, J., Widimský, P., Tousek, P., Petrák, O., Curila, K., and Waldauf, P. (2015). Randomized comparison of renal denervation versus intensified pharmacotherapy including spironolactone in true-resistant hypertension. Six months results from the Prague-15 Study. Hypertension 65, 407-413. doi: 10.1161/HYPERTENSIONAHA.114.04019

Salles, G. F., Cardoso, C. R., and Muxfeldt, E. S. (2008). Prognostic influence of office and ambulatory blood pressures in resistant hypertension. Arch. Intern. Med. 168, 2340-2346. doi: 10.1001/archinte.168.21.2340

Schmieder, R. E. (2014). How should data from SYMPLICITY HTN-3 be interpreted? Nat. Rev. Cardiol. 11, 375-376. doi: 10.1038/nrcardio.2014.70

Schmieder, R. E., Redon, J., Grassi, G., Kjeldsen, S. E., Mancia, G., and Narkiewicz, K. (2012). ESH position paper: renal denervation-an interventional therapy of resistant hypertension. J. Hypertens 30, 837-841. doi: 10.1097/HJH.0b013e328352ce78

Schmieder, R. E., Redon, J., Grassi, G., Kjeldsen, S. E., Mancia, G., and Narkiewicz, K. (2013). Updated ESH position paper on interventional therapy of resistant hypertension. Eur. Intervent. 9, R58-R66. doi: 10.4244/EIJV9SRA11
Shun-Shin, M. J., Howard, J. P., and Francis, D. P. (2014). Removing the hype from hypertension. Symplicity HTN-3 illustrates the importance of randomisation and blinding for exciting new treatments. BMJ 348:g1937. doi: 10.1136/bmj.g1937

Smithwick, R. H., and Thompson, J. E. (1953). Splanchnicectomy for essential hypertension, results in 1,266 cases. JAMA 152, 1501-1504. doi: 10.1001/jama.1953.03690160001001

Staessen, J. A., Thijs, L., Bieniaszewski, L., O’Brien, E. T., Palatini, P., and Davidson, C. (1996). Ambulatory monitoring uncorrected for placebo overestimates longterm antihypertensive action. Systolic Hypertension in Europe (SYST-EUR) Trial Investigators. Hypertension 27, 414-420. doi: 10.1161/01.HYP.27.3.414

Strauch, B., Petrák, O., Zelinka, T., Rosa, J., Somlóová, Z., and Indra, T. (2013). Precise assessment of noncompliance with the antihypertensive therapy in patients with resistant hypertension using toxicological serum analysis. J. Hypertens 31, 2455-2461. doi: 10.1097/HJH.0b013e3283652c61

Tomaszewski, M., White, C., Patel, P., Masca, N., Damani, R., and Hepworth, J. (2014). High rates of non-adherence to antihypertensive treatment revealed by high-performance liquid chromatography-tandem mass spectrometry (HP LC-MS/MS) urine analysis. Heart 100, 855-861. doi: 10.1136/heartjnl-2013305063

White, W. B., Turner, J. R., Sica, D. A., Bisognano, J. D., Calhoun, D. A., Townsend, R. R., et al. (2014). Detection, evaluation, and treatment of severe and resistant hypertension: Proceedings from an American Society of Hypertension Interactive Forum held in Bethesda, MD, USA, October 10th 2013. J. Am. Soc. Hypertens 8, 743-757. doi: 10.1016/j.jash.2014.06.005

Conflict of Interest Statement: Sverre E. Kjeldsen, Fadl Elmula M. Fadl Elmula and Anne C. Larstorp have been supported by grant from Hemo Sapiens; and Sverre E. Kjeldsen by unrestricted grants from AZ and Pronova. Sverre E. Kjeldsen has received lecture and consultancy honoraria from AZ, Bayer, Medtronic, MSD, Novartis, Serodus, and Takeda, and royalty payments from Gyldendal (publisher). Fadl Elmula M. Fadl Elmula has received speaker honorarium from Medtronic and Hemo Sapiens and Anne C. Larstorp from Hemo Sapiens and Merck et Co. Alexandre Persu declares no conflict of interest.

Received: 21 October 2014; accepted: 08 January 2015; published online: 09 February 2015.

Citation: Fadl Elmula FE, Larstorp AC, Kjeldsen SE, Persu A, Jin Y and Staessen JA (2015) Renal sympathetic denervation after Symplicity HTN-3 and therapeutic drug monitoring in severe hypertension. Front. Physiol. 6:9. doi: 10.3389/fphys.2015.00009 This article was submitted to Integrative Physiology, a section of the journal Frontiers in Physiology.

Copyright @ 2015 Fadl Elmula, Larstorp, Kjeldsen, Persu, Jin and Staessen. This is an open-access article distributed under the terms of the Creative Commons Attribution License (CC BY). The use, distribution or reproduction in other forums is permitted, provided the original author(s) or licensor are credited and that the original publication in this journal is cited, in accordance with accepted academic practice. No use, distribution or reproduction is permitted which does not comply with these terms. 